\title{
A Two Stage Buck Boost Converter With Isolation As A High Power Factor Supply For Power-LED Lamps
}

\author{
Lekshmi Sasidharan $^{1}$, Jeneesh Scaria ${ }^{2}$ \\ PG Student, Dept. of EEE, Mangalam College of Engineering, Kottayam, Kerala, India ${ }^{1}$ \\ Assistant professor, Dept. of EEE, Mangalam College of Engineering, Kottayam, Kerala, India ${ }^{2}$
}

\begin{abstract}
In recent years, power converters are used to get high power factor for low power applications. In this work, the design and development of a DC-DC Converter using two stage buck-boost converter with isolation operation as high-power-factor offline power supply for power-LED lamps is discussed. This converter is suitable for low power application such as a matrix LED lighting system. The advantage of this converter is that instead of using two controlled switches as in case of a conventional converter, this circuit uses one MOSFET as a switch. The circuit uses two inductors and two capacitors as energy transferring elements that are able to provide a good quality, high efficiency power supply to the load. The design of this converter is simulated with closed loop control using a PI controller circuit. The main feature of this circuit is that have a galvanic isolation between the load and the source. Thus, by a suitable controller and galvanic isolation, the ripple magnitude in the output is reduced considerably. A design example for a $70-\mathrm{W}$ converter supplied from a $230 \mathrm{~V} / 50 \mathrm{~Hz}$ mains for street lighting applications is shown. Simulation results demonstrate that the power factor of the closed-loop proposed converter is 0.993 and the output voltage of the designed controller can be stably maintained at $200 \mathrm{~V}$. The experimental results are shown to substantiate this design. This converter is used to provide power factor correction in streetlight application. The simulation studies using MATLAB/Simulink is also presented.
\end{abstract}

KEYWORDS: Two Stage Buck Boost Converter(TSBB), Power LED Lamps, Discontinous Conduction Mode(DCM), Continuous Conduction Mode(CCM), Galvanic Isolation.

\section{I.INTRODUCTION}

As generally acknowledged, due to the high efficiency of the light-emitting diodes (LEDs), the LED is getting more and more attractive in the world, particularly for industrial applications in the street light. However, the high efficiency LED system needs the high efficiency power supply to feed the LED. The tungsten lamps provide only $8-10 \mathrm{~lm} / \mathrm{W}$ and very inefficient, they are then replaced by fluroscent lamps now with the efficiency of an LED is as high as $100 \mathrm{~lm} / \mathrm{W}$ [2] they are mostly preferred. The main drawback of these LEDs is they needs constant voltage as input and they need current limiter before the input of the LED.

In general lighting applications, high power factor can be achieved using either a passive circuit or an active circuit. The passive circuit consist of inductors and capacitors together with uncontrolled rectifier. This is a good solution to achieve high power factor and does not generate electromagnetic interferences (EMI). In active power factor correction circuit, switch mode power supplies are used to achieve high power factor, low THD, and good output voltage regulation. Active power factor correction circuit is divided in to two categories, the two stage and single stage approaches.

A review of literature shows that a variety of LED power supplies and driver solutions, which can accurately control the current of the LED while achieving a near-unity input power factor, have been proposed [8],[10]. This drive is currently implemented with power electronic stages based on switch mode power supplies (SMPS). However, an electrolytic capacitor is required in these applications. Unfortunately, the operating life of such capacitors is by far shorter than the life of the HB LEDs, and usually are the shortest of all the devices in the power supply. Thus, removing the electrolytic capacitor would imply a remarkable increase in the operating life and reliability of the system [3],[4].

PFC converters can be classified into two types: two-stage and single-stage. Two-stage PFC converters consist of a PFC stage and a dc/dc stage. Single-stage PFC converters integrate the PFC stage and the dc/dc stage, leading to simple 
 \\ International Journal of Advanced Research in Electrical, Electronics and Instrumentation Engineering
}

\author{
(An ISO 3297: 2007 Certified Organization)
}

\section{Vol. 3, Issue 8, August 2014}

topology and low cost. They are suitable for low-power applications [7]. The simplest active PFC circuits are implemented with a single-stage that makes the power factor correction. The most common single-stage topology used is the flyback converter [5], [6] working in Discontinuous Conduction Mode (DCM), being called DCM flyback PFC converter. The main drawbacks of these pre-regulators are, by one hand, the high peak current stresses caused by the DCM and serious EMI problem [3] and, by the other, the poor dynamics that these converters perform due to the lowpass filter $(10 \mathrm{~Hz}-20 \mathrm{~Hz})$ needed to reduce the input line current total harmonic distortion (THD). Therefore, if dimming operation is required, which must be done at frequencies above $200 \mathrm{~Hz}$, these single stage solutions are not feasible . Attending to the re asons exposed above, a two-stage is needed so the Power Factor Correction can be done properly and a fast enough output dynamics is obtained.

A two stage buck boost converter (TSBB) is proposed to supply power LED lamps from the ac mains, providing high power factor (PF), low LED current ripple, and high efficiency. With the double buck boost converter, two converters are cascaded with a single switch and it includes two low value inductors and capacitors and suitably placed diodes thus the LED lamp can be supplied with low ripple and high efficiency power. In Section II, the working of TSBB converter with isolation [1] is presented. In Section III, the analysis and design of the TSBB converter [1] in various mode is detailed. In Section IV, Simulation results of TSBB converter with isolation is discussed. Section V discusses on the laboratory prototype made and in the Section VI results and conclusions are discussed.

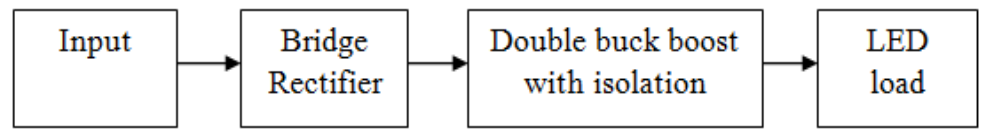

Fig 1: Block Diagram of Circuit Diagram

\section{TWO STAGE BUCK BOOST CONVERTER}

Fig 2 shows the schematic circuit of the TSBB converter. This converter acts as a two buck-boost converters which are electrically isolated and connected to the load. The input buck-boost converter is made up by $L_{1}, D_{2}, D_{3}, C_{B}$ and $M_{1}$ and the output buck-boost converter acts as a flyback converter due to addition of galvanic isolation and comprises of $\mathrm{L}_{\mathrm{O}}$, $\mathrm{D}_{3}, \mathrm{C}_{\mathrm{O}}, \mathrm{M}_{1}$. The reversing polarity produced by the first converter in the capacitor $\mathrm{CB}$ is corrected by the second converter, given a positive output voltage with respect to ground, thereby simplifying the measurement of the load current, in the closed-loop operation, also reducing the sensing circuitry and hence the cost.

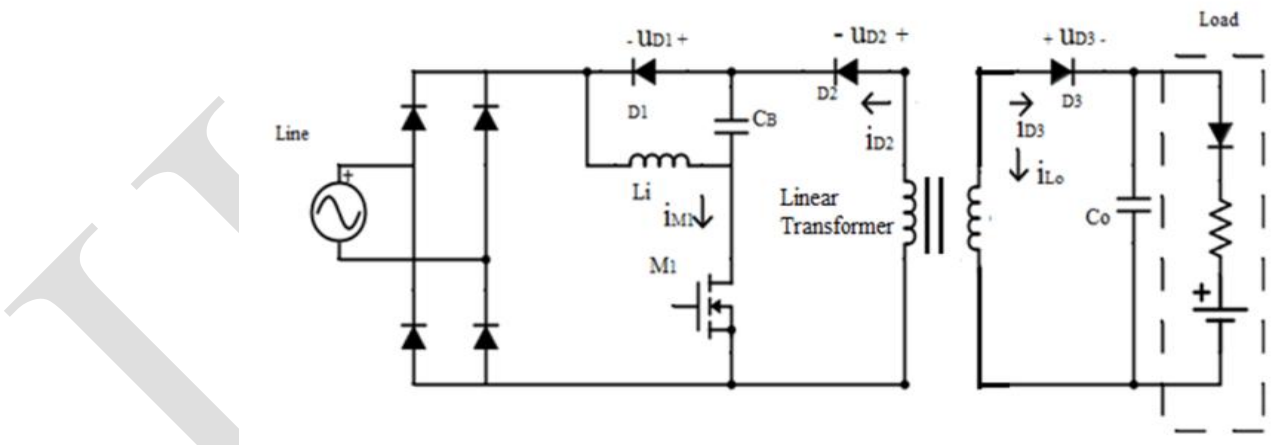

Fig 2: Schematic circuit of a TSBB converter with isolation

The input inductor $\mathrm{L}_{\mathrm{i}}$ is operating in discontinuous conduction mode (DCM), the average current through the line will be almost in phase with the line voltage, which results in a line power factor near unity, this is important if the converter operates from mains voltage in a grid. Also, the output inductance $\mathrm{L}_{\mathrm{O}}$ can be operated either in continuous conduction mode $(\mathrm{CCM})$ or discontinuous conduction mode. DCM results in a bus voltage across $\mathrm{C}_{\mathrm{B}}$ that is independent of duty cycle and output power. But there is a drawback in DCM, it requires a higher value of the output capacitance to achieve low current ripple through the load. So to avoid high current ripple in the output and to reduce the value of the output capacitance, CCM operation is preferred. Inaddition to above, to reduce the ripple voltage occurring at low frequencies, 
 \\ International Journal of Advanced Research in Electrical, Electronics and Instrumentation Engineering
}

\author{
(An ISO 3297: 2007 Certified Organization)
}

\section{Vol. 3, Issue 8, August 2014}

the second stage of the TSBB is operated with $\mathrm{D}=50 \%$ (duty cycle), since the duty cycle is multiplied by the buckboost converter voltage ratio. In this way, it will be possible even to use a film capacitor to implement the output capacitance; this gives the TSBB converter longer life rating and improved efficiency over the use of electrolytic capacitors.

Moreover, with a careful design of the converter, the bus capacitor can also be made low enough to be implemented with film technology, thus avoiding the low life rating electrolytic capacitors in the whole converter. This implies the design of the converter so that it operates with a $\alpha$ lower than 0.5 . In this manner, the output converter voltage ratio will be lower than one, thus reducing the low frequency voltage ripple in the same amount.

\section{(a) Need for Isolation}

Non isolated switching regulators are very commonly used regulators because of low cost and simple. These converters suffer from one disadvantage in that there is an electrical connection between the input and output. Many safety agency bodies require a separation from the applied input voltage and the output voltage which is often user accessible. An isolated DC-DC converter will have a high frequency transformer providing that barrier. This barrier can withstand anything from a few hundred volts to several thousand volts, as is required for medical application.In this particular LED application, these are widely used for high power lighting applications .therefore it is essential to isolate higher power load and low power control part. A flyback transformer is used here to provide the requirement.

\section{ANALYSIS OF TSBB CONVERTER}

In this section, the TSBB converter with isolation is analysed when operated from the main voltage, achieving a near unity input PF and a low ripple current through the power LED load. The line voltage is assumed to be sinusoidal waveform given as $v_{g}(t)=V_{g} \sin \omega_{L} t$.

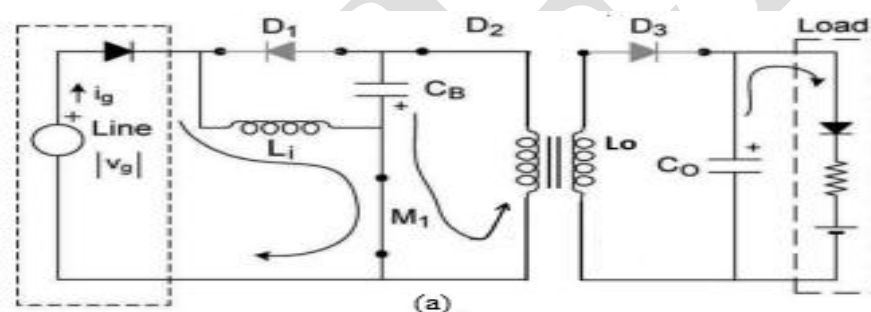

(a)

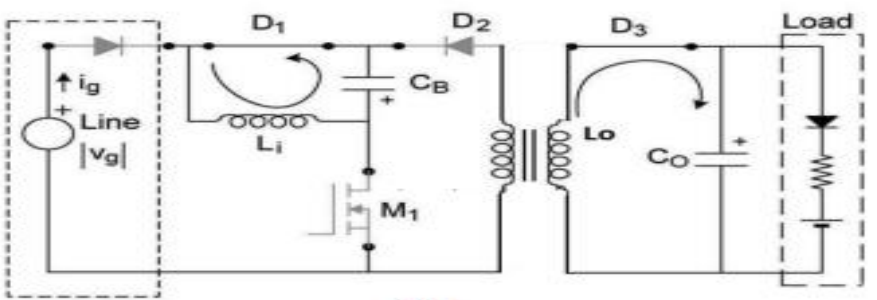

(b)

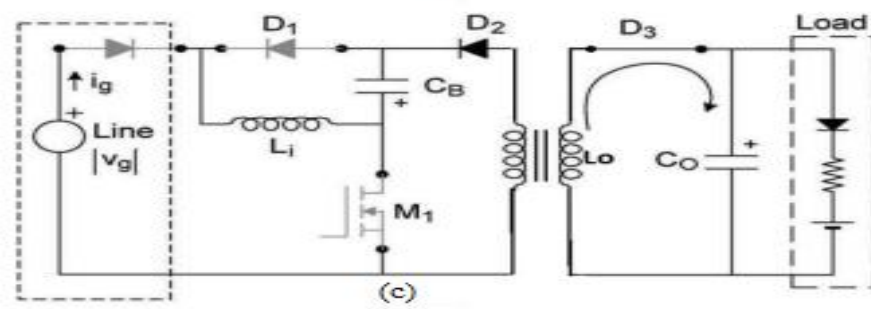

Fig: 3 Equivalent circuits for the operation of the TSBB converter. (a) Interval I: $0<\mathrm{t}<\mathrm{DTS}$. (b) Interval II: DTS < $t$ $<$ DTS + t1. (c) Interval III: DTS $+\mathrm{t} 1<\mathrm{t}<\mathrm{TS}$. 
 \\ International Journal of Advanced Research in Electrical, Electronics and Instrumentation Engineering \\ (An ISO 3297: 2007 Certified Organization) \\ Vol. 3, Issue 8, August 2014}

\section{(a) Line Current}

The input current ig corresponds to the current through the inductance Li during the time interval 0-DTS, where D is the transistor duty cycle and TS is the transistor switching period. This current is modulated by the rectified line voltage [1]. Thus, the value of the input current averaged at line frequency can be calculated as follows [1].

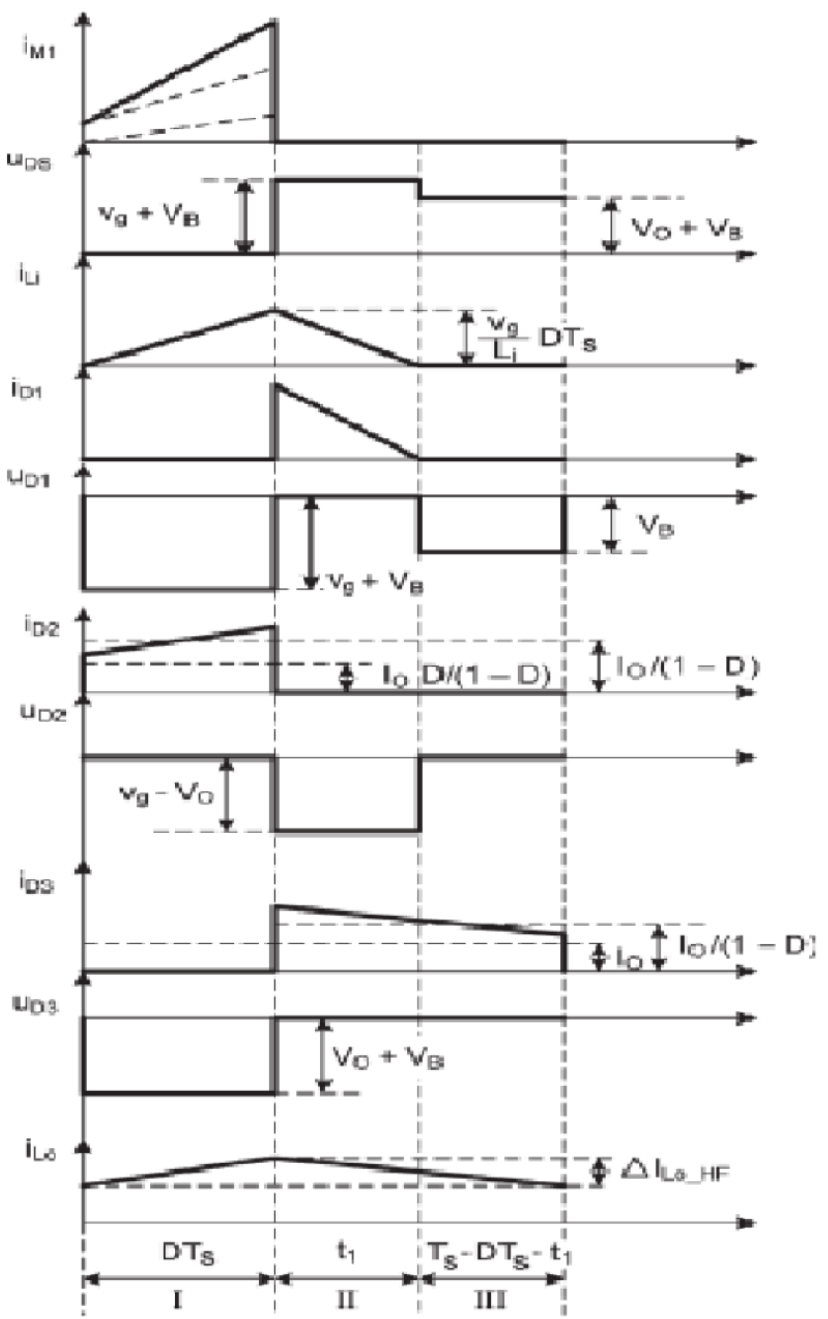

Fig: 4 Main waveforms of the Two Stage Buck Boost converter within a high frequency switching period around the peak line voltage.

$$
<i_{g}>=\frac{D^{2} V_{g}}{2 L_{i} f_{S}} \sin \omega_{L} t
$$

Where, fs is the switching frequency, $\mathrm{Vg}$ is the peak line voltage and $\omega_{L}$ is the line angular frequency. From the above equation, the averaged input current is a sinusoidal waveform that will provide an input PF close to unity once filtered by the input electromagnetic interference (EMI) filter. The mean input power Pi can be calculated as,

$$
P_{g}=\frac{D^{2} V_{g}^{2}}{2 L_{i} f_{S}}
$$




\section{8 \\ ISSN (Print) : 2320 - 3765 \\ ISSN (Online): 2278 - 8875 \\ International Journal of Advanced Research in Electrical, Electronics and Instrumentation Engineering \\ (An ISO 3297: 2007 Certified Organization)}

Vol. 3, Issue 8, August 2014

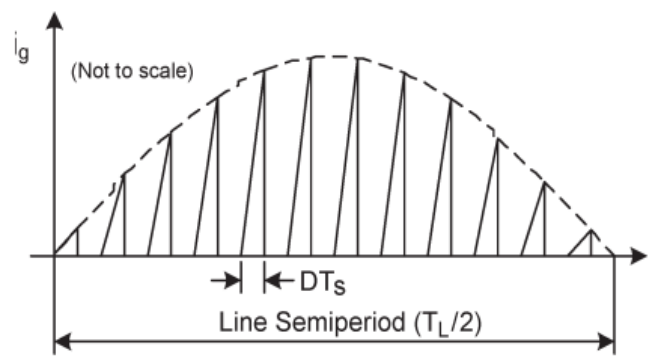

Fig: 5 Input Current waveform.

\section{(b) Output and Bus Voltages}

The output voltage $\mathrm{V}_{\mathrm{O}}$ for the ideal converter can be obtained by equating input and output power is obtained as follows:

$$
P_{O}=\frac{V_{O}^{2}}{R}
$$

Where, $R$ being the static equivalent resistance of the LED load which can be obtained by the ratio between the dc values of LED voltage (VLED) and current (ILED) at each operating point.

$$
R=\frac{V_{L E D}}{I_{L E D}}=\frac{V_{\gamma}+R_{\gamma} I_{L E D}}{I_{L E D}}=\frac{V_{\gamma}}{I_{L E D}}+R_{\gamma}
$$

Where, $V_{\gamma}$ and $R_{\gamma}$ are the voltage and resistance parameters of the LED lamp. Assuming 100\% efficiency, by equaling (2) and (3), the output voltage is obtained by,

$$
V_{O}=\frac{D V_{g}}{2 \sqrt{K}}
$$

Where, $\mathrm{K}$ is a nondimensional factor given by,

$$
K=\frac{f_{s} L_{i}}{R}
$$

Since the output stage corresponds to a buck boost converter operating in CCM, the bus voltage $V_{B}$ will be,

$$
V_{B}=\frac{1-D}{D} V_{O}=\frac{(1-D) V_{g}}{2 \sqrt{K}}
$$

As can be seen from (5) and (7), when operating the input stage in DCM and the output stage in CCM, the bus and output voltages are reversely dependent on the duty cycle. The sum of both voltages does not depend on the duty cycle, being only proportional to the line peak voltage,

$$
V_{B}+V_{O}=\frac{V_{g}}{2 \sqrt{K}}
$$

\section{(c) Energy Transferring Components or Reactive Component}

The value of the energy transferring element at the input which is $\mathrm{Li}$ is calculated based on the output power and assuming $100 \%$ efficiency the value of inductance is so obtained to be,

$$
L_{i}=\frac{D^{2} V_{g}^{2}}{4 P_{o} f_{s}}
$$

The bus capacitor $C_{B}$ is calculated to limit the low frequency ripple of the bus voltage, which is the voltage applied to the second stage. The current through this capacitor is given by the currents through diodes $D_{1}$ and $D_{2}$. In these diodes, 
 \\ International Journal of Advanced Research in Electrical, Electronics and Instrumentation Engineering \\ (An ISO 3297: 2007 Certified Organization) \\ Vol. 3, Issue 8, August 2014}

only the current through $D_{1}$ is modulated by a rectified line frequency. In order to calculate the bus ripple, the low frequency component of the current through $D_{1}$ must be obtained. The average current through $D_{1}$ is,

$$
<i_{D 1}>=\frac{1}{T_{S}} \frac{i_{D 1-\text { peak }} t_{1}}{2}
$$

Where, $i_{D 1-\text { peak }}$ is the peak current through $D_{1}$ in each switching period and $t_{1}$ is the time needed by this current to reach zero. Both values changing after double the line frequency and have the following values.

$$
\begin{aligned}
& i_{D 1-\text { peak }}=\frac{V_{g}}{L_{i}} D T_{S} \\
& t_{1}=\frac{D T_{S} V_{g}}{V_{B}}
\end{aligned}
$$

$D_{1}$ average current is,

$$
<i_{D 1}>=\frac{D^{2}}{2 V_{B} f_{S} L_{i}} V_{g}^{2}=\frac{D^{2}}{2 V_{B} f_{S} L_{i}} V_{g}^{2} \sin ^{2} \omega_{L} t
$$

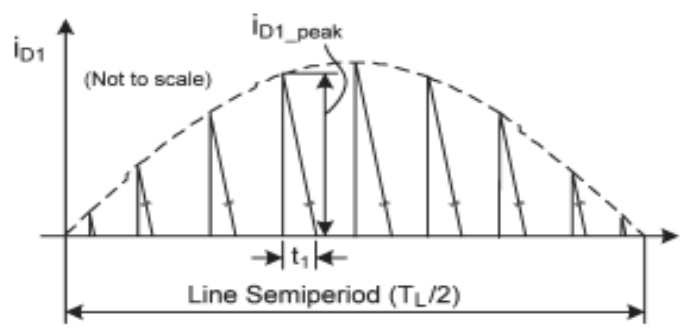

Fig: 6 Current waveform through diode D1.

Above equation becomes,

$$
<i_{D 1}>=\frac{D^{2} V_{g}^{2}}{2 V_{B} f_{S} L_{i}}\left(\frac{1}{2}-\frac{1}{2} \cos 2 \omega_{L} t\right)
$$

Then, the low frequency ac component circulating through $D_{1}$ and $C_{B}$ is given by,

$$
<i_{D 1}>_{a c}=\frac{D^{2} V_{g}^{2}}{4 V_{B} f_{s} L_{i}} \cos 2 \omega_{L} t
$$

The low frequency peak to peak ripple voltage across capacitor $C_{B}, \Delta V_{B_{-} L F}$ can be obtained as,

$$
\Delta V_{B_{-} L F}=\frac{D^{2} V_{g}^{2}}{8 \pi V_{B} L_{i} C_{B} f_{s} f_{L}}
$$

The bus capacitance $C_{B}$, for a given peak-to-peak ripple in the bus voltage is then calculated from (17) as follows:

$$
C_{B}=\frac{D^{2} V_{g}^{2}}{8 \pi V_{B} L_{i} \Delta V_{B_{-} L F} f_{S} f_{L}}
$$

Note that, as long as the output buck-boost converter operates in CCM, the LED current ripple at low frequency depends only on the bus voltage ripple and thus, on the bus capacitance $\mathrm{C}_{\mathrm{B}}$. The output capacitance $\mathrm{C}_{\mathrm{O}}$ has no effect on this low frequency ripple. Finally, the output inductance and capacitance $\mathrm{L}_{\mathrm{O}}$ and $\mathrm{C}_{\mathrm{O}}$ are obtained using the well known expressions for a buck-boost converter operating in CCM, 
 \\ International Journal of Advanced Research in Electrical, Electronics and Instrumentation Engineering}

(An ISO 3297: 2007 Certified Organization)

Vol. 3, Issue 8, August 2014

$$
\begin{array}{r}
L_{O}=\frac{D V_{B}}{0.5 \Delta I_{L O_{H} H F} f_{S}} \\
C_{O}=\frac{D I_{O}}{\Delta V_{O-H F} f_{S}}
\end{array}
$$

Where, $\Delta I_{L_{-} H F}$ is the $\mathrm{L}_{\mathrm{O}}$ high frequency peak-peak current ripple, $\Delta V_{O_{-} H F}$ is the high frequency peak-to-peak output voltage ripple, and $I_{O}$ is the dc current through the LED load.

\section{SIMULATION RESULT AND DISCUSSIONS}

Simulation of the TSBB converter with isolation was done using MATLAB Software. Simulation is done with the help of Simulink of Matlab 7.8.0 version. MATLAB is one of the most popular software in control field and its graphical simulation environment SIMULINK is very suitable for dynamic system simulation because there are plenty of toolboxes and modules. Simulink is a software package for modeling, simulating, and analyzing dynamic systems. Simulation results are very useful for deciding the ratings of the different components for hardware implementation. With the help of simulation results, the relevant waveforms are successfully obtained.

A simulation prototype for a street lighting application has been developed using MATLAB/SIMULINK. The lamp is formed by $60 \mathrm{LW}$ W5SG power LEDs by Osram in a series array. The load rating current is $350 \mathrm{~mA}$, with an output power of $70 \mathrm{Wand}$ a total luminous flux of $1500 \mathrm{~lm}$. The load was tested at the laboratory, obtaining the following model parameters: $\mathrm{V} \gamma=170 \mathrm{~V}$ and $\mathrm{R} \gamma=87 \Omega$. The equivalent load resistance at nominal power is $\mathrm{R}=570 \Omega$. The selected switching frequency is $50 \mathrm{kHz}$. The line voltage is $230 \mathrm{Vrms}$ with a $50-\mathrm{Hz}$ line frequency. The converter must admit at least $10 \%$ line voltage variation, assuring constant current through the load. The switching frequency is assumed to be $50 \mathrm{KHz}$. The output voltage obtained to be $200 \mathrm{~V}$.

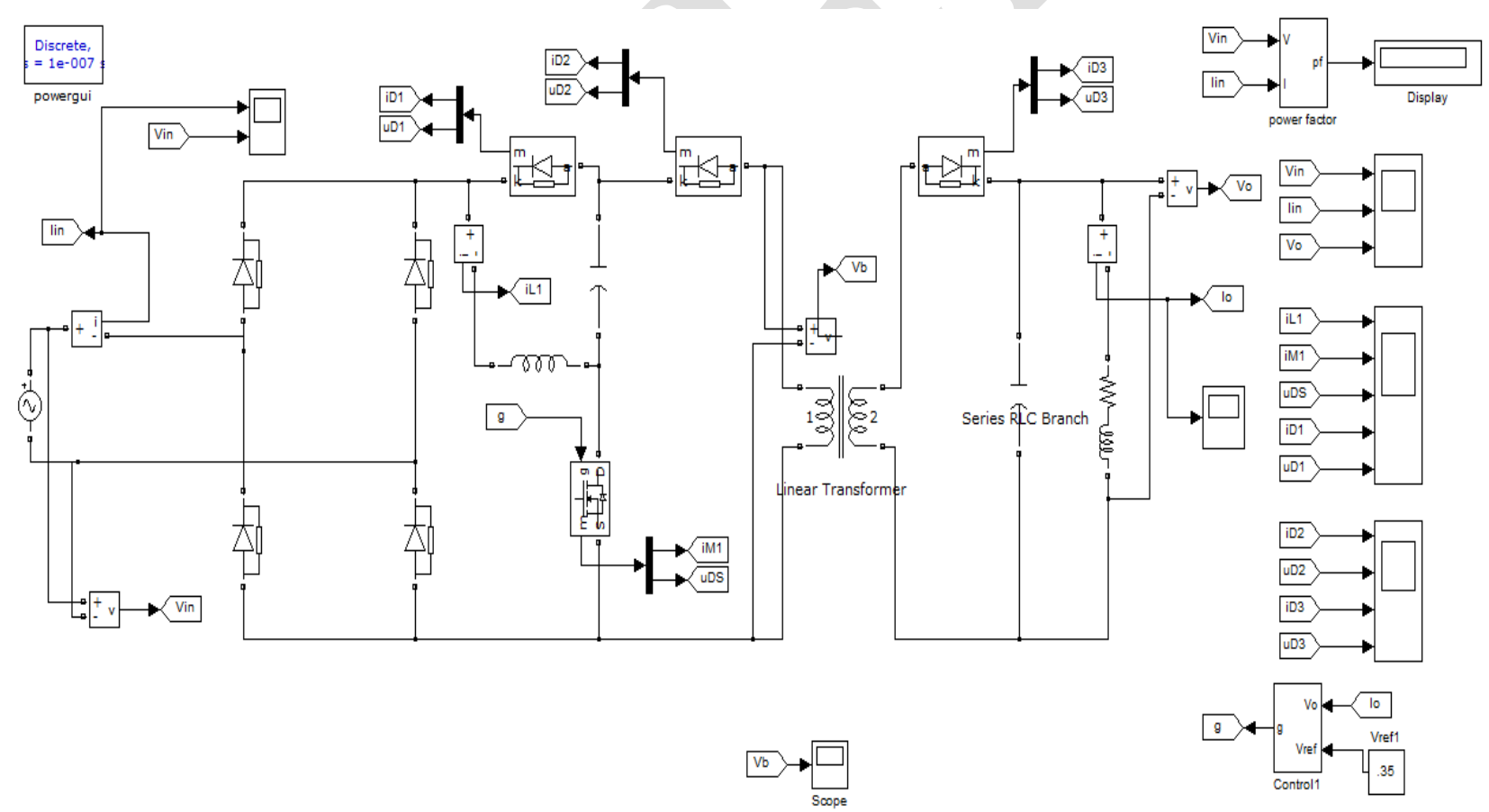

Fig: 7 Simulation circuit of Two Stage Buck Boost converter with Isolation.

The circuit configuration shown in fig 7, TSBB converter with isolation in closed loop mode using a PI controller. The values of the PI controller elements are so chosen to give a reduced steady state error. 
 \\ International Journal of Advanced Research in Electrical, Electronics and Instrumentation Engineering \\ (An ISO 3297: 2007 Certified Organization)}

\section{Vol. 3, Issue 8, August 2014}
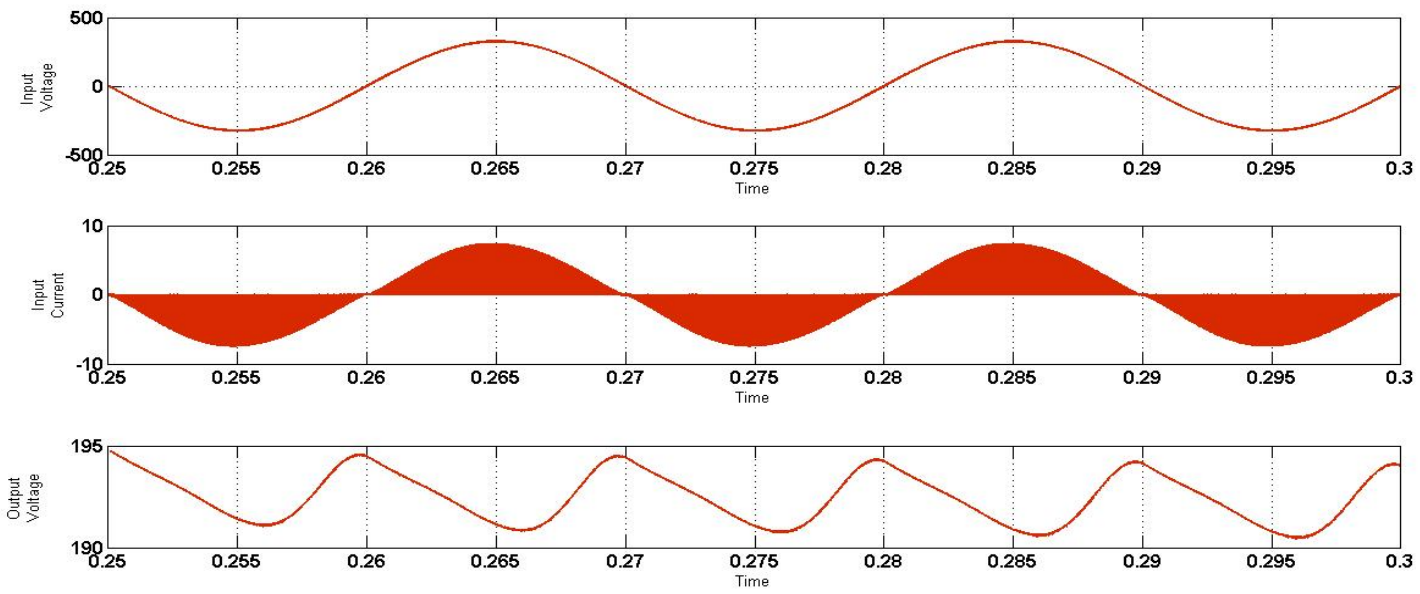

Fig: 8 (a) Input Voltage (b) Input Current (c) Output Voltage.

The figure 8 represents the input voltage and current waveform of the proposed converter. From the graph we can see that the input voltage is inphase with averaged input current, so the power factor becomes unity and it also shows the output voltage with low ripple current of the proposed converter.
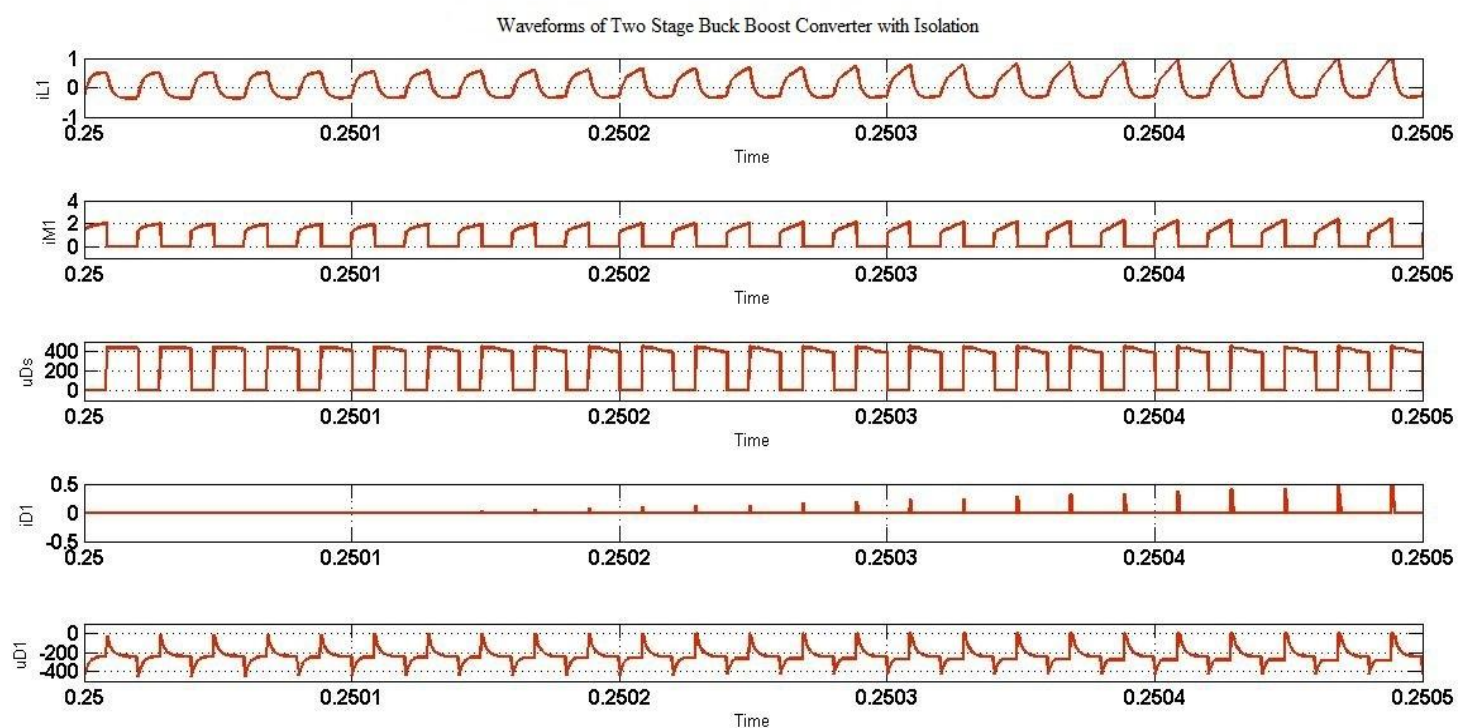

Fig: 9 (a) Current through inductor $\mathrm{L}_{1}$ (b) Current through Switch (c) Voltage across Switch (d) Current through diode $\mathrm{D}_{1}$ (e) Voltage across diode $\mathrm{D}_{1}$

The figure 9 represents the current and voltage waveform through the inductor and switch and also shows the voltage and current waveforms across diode D3. 
International Journal of Advanced Research in Electrical, Electronics and Instrumentation Engineering

(An ISO 3297: 2007 Certified Organization)

\section{Vol. 3, Issue 8, August 2014}
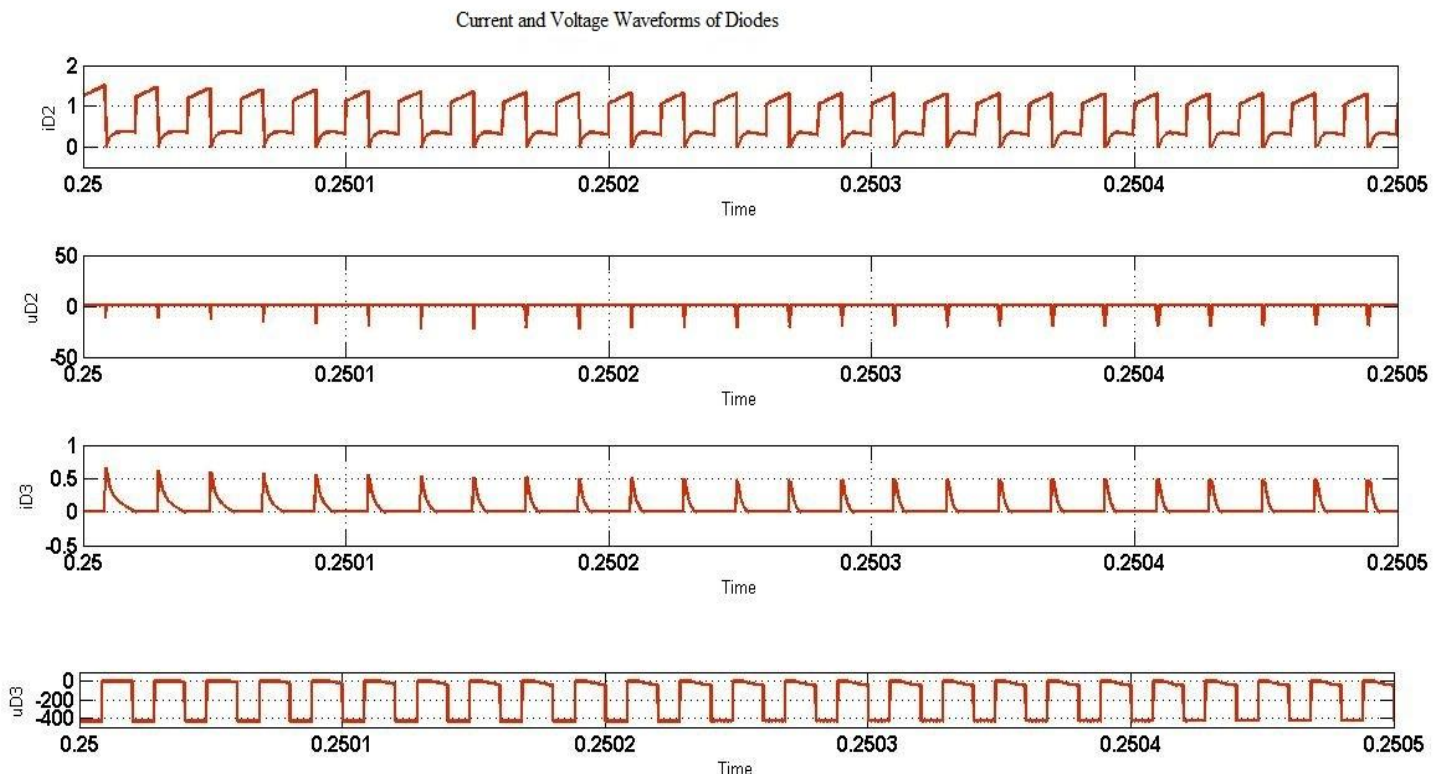

Fig: 10 (a) Current through diode $\mathrm{D}_{2}$ (b) Voltage across diode $\mathrm{D}_{2}$ (c) Current through diode $\mathrm{D}_{3}$ (d) Voltage across diode $\mathrm{D}_{3}$

The figure 10 represents current and voltage waveforms across the diode D1and also shows the voltage and current across diode D2.

\section{CONCLUSIONS}

A two stage buck boost converter (TSBB) with isolation has been successfully simulated in this paper. This circuit configuration is suitable for low power applications. In closed loop mode suitable controller namely the PI controller was used. From the above section, it is evident from the results that the configuration of TSBB with isolation in closed loop is efficient compared to the converters using more than one switch.

The added advantage of this converter is that this is suitable for power converters used for medical applications where isolation is essential. Though isolation may end up in increase of cost, it is a safety aspect that cannot be neglected in certain application. Thus TSBB converter with isolation in closed loop mode is more efficient, safe and reliable for any low power loads.

\section{REFERENCES}

[1] J.Marcos Alonso, Juan Vina, David Gacio Vaquero, "Analysis and Design of the Integrated Double Buck Boost Converter as a High power factor driver for power LED Lamps", IEEE Transactions on industrial electronics, vol.59, no.4, April 2012.

[2] D. Gacio, J. M. Alonso, J. Garcia, L. Campa, M. Crespo, and M. Rico- Secades, "High frequency PWM dimming technique for high power factor converters in LED lighting", in Proc. 25th Annu. IEEE APEC, Feb. 21-25, 2010, pp. 743-749.

[3] J. Garcia, A. J. Calleja, E. L. Corominas, D. Gacio, and J. Ribas, "Electronic driver without electrolytic capacitor for dimming high brightness LEDs", in Proc. 35th Annu. IEEE IECON, Nov. 3 -5, 2009, pp. 3518-3523.

[4] Y.X.Qin, H.S.H. Chung, D.Y.Lin, S.Y.R.hui, "Current Source Ballast for high Power Lighting Emitting Diodes without Electrolytic Capacitor", IEEE IECON 2008, 34th Industrial electronics Annual Conference, Proceedings of, pp. 1968- 1973, 10-13 Nov. 2008, Orlando, Florida, USA

[5] Chien Ming Wang, "A novel single stage high power factor electronic ballast with symmetrical half bridge topology", in IEEE Transactions. Industrial electronics. vol.55 no-2 pp 969-972, feb 2008.

[6] Tsorng-juu liang, Chien-ming huang, and Jiann-fuh chen, "Two stage high power factor electronic ballast for metal halide lamps", in IEEE Transactions on Power electronics, vol.24, no.12 december 2009.

[7] John C, W. Lam and Praveen k jain "A high-power-factor single-stage single-switch electronic ballast for compact fluorescent lamps", in IEEE Transactions on Power electronics, vol.25, no.8, august 2010. 


\section{9 \\ ISSN (Print) : $2320-3765$ \\ ISSN (Online): 2278 - 8875 \\ International Journal of Advanced Research in Electrical, Electronics and Instrumentation Engineering \\ (An ISO 3297: 2007 Certified Organization) \\ Vol. 3, Issue 8, August 2014}

[8] H. Broeck, G. Sauerl"ander, and M. Wendt, "Power driver topologies and control schemes for LEDs", in Proc. IEEE APEC 2007, pp. 13191325.

[9] J. Sebasti'an, D. G. Lamar,M. Arias, M. Rodr'iguez, andM.M. Hernando, “A very simple control strategy for power factor correctors driving high brightness light-emitting diodes, $\|$ in Proc. IEEE APEC 2008, pp. 537-543.

[10] S. Y. (ron) hui, Sinanli, Xuehuitao,Wuchen, and W.M.ng , "A novel passive offline led driver with long lifetime", in IEEE Transactions on Power electronics, vol.25, no.10, October 2010.

[11] Xiaogao Xie, Jian Wang, Chen Zhao, Qiang Lu, and Shirong Liu, "A Novel Output Current Estimation and Regulation Circuit for Primary Side Controlled High Power Factor Single-Stage Flyback LED Driver", IEEE Transactions on Power Electronics, vol.27, no.11, November 2012

[12] K. I. Hwu, Y.T.Yau,, and Li-Ling Lee, "Powering LED Using High efficiency SR Flyback Converter", in IEEE Transactions on Industrial Electrons vol.47, no.1, Jan/Feb 2011.

[13] Hongbo ma, Jih-sheng lai, Quanyuan feng, Wensong yu, Cong zheng, and Zheng zhao, "A novel valley-fill sepic-derived power supply without electrolytic capacitors for led lighting application”, in IEEE Transactions on Power electronics, vol.27, no.6, june 2012.

\section{BIOGRAPHY}

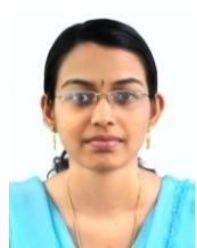

Lekshmi Saidharan ${ }^{1}$ has completed her B. Tech in Electrical and Electronics Engineering from Sree Buddha College of Engineering, Pattoor, Alappuzha, Kerala, India and doing M. Tech in Mangalam College of Engineering, Kottayam, Kerala, India.

Jeneesh Scaria ${ }^{2}$ currently holds the post of Assistant Professor in the Department of Electrical and Electronics, Mangalam College of Engineering, Kottayam, Kerala, India. 